Social Support in Couples: An Examination of Gender Differences Using Self-Report and Observational Methods

Lesley L. Verhofstadt ${ }^{(1)}$, Ann Buysse ${ }^{(1)}$, William Ickes ${ }^{(2)}$, \& Kim G. De Corte ${ }^{(1)}$

${ }^{(1)}$ Department of Experimental Clinical and Health Psychology Ghent University, Ghent, Belgium

${ }^{(2)}$ Department of Psychology,

University of Texas at Arlington, Arlington, Texas, USA

SUBMISSION DATE: August $23^{\text {th }}, 2005$ 


\begin{abstract}
Two studies were conducted to examine gender differences in spousal support. Study 1 was a survey study involving 458 married couples, and Study 2 was an observational study involving 32 married couples. Self-reports were used in both studies to assess spouses' support behaviors and perceived support. These measures were supplemented in Study 2 with measures of observed support behavior and on-line perceived support, as assessed during support interactions. Overall, the self-report measures yielded significant gender differences in support soliciting and support provision, whereas the observational measures did not. Furthermore, the results concerning global and on-line perceived support and support profiles were inconsistent with the "support gap" perspective. These findings were discussed in light of the existing research on gender differences in support and marriage.
\end{abstract}

KEY WORDS: social support, marriage, gender differences, self-report, observational methods 


\section{Social Support in Couples: An Examination of Gender Differences \\ Using Self-Report and Observational Methods}

Spouses are often named as frequent and important sources of social support, and support from sources outside the marriage cannot compensate for a lack of spousal support (see Pasch, Bradbury, \& Davila, 1997). Besides the beneficial role of spousal support in promoting individual adjustment (see Cohen, Gottlieb, \& Underwood, 2000), it is also important for relationship maintenance (see Cutrona, 1996). Evidence has accumulated showing that spousal support is positively associated with marital satisfaction (Pasch \& Bradbury, 1998; Verhofstadt, Buysse, \& Rosseel, 2005).

A popular view holds that women receive less support from their spouses than men, and that the support they receive is less helpful than what they provide to their husbands (e.g., Belle, 1982). According to this perspective, men and women also have different styles of providing support: Men are presumably more likely to offer instrumental support, whereas women are more likely to provide emotional support (Tannen, 1990). This so-called "support gap" was proposed more than 20 years ago, but it is still represented as one of the unchanging asymmetries that characterize most marriages (Steil, 2000). Although this marital support gap is widely accepted as fact and is increasingly promulgated in the literature, its empirical basis is unclear.

In our view, this polarized portrayal of husbands and wives characteristically providing support to one another has largely emerged from generalizations of gender differences across different relationship types, across different components of the support construct, and across different research methods. Whether the "support gap" actually exists within most marriages is a question that remains to be answered. If the existing literature that bears on this question is examined closely, the following cautionary observations should be made. 
First, few studies have actually examined the claim of gender differences in social support in the context of intimate relationships (Pasch et al., 1997). Consequently, the claim of a marital support gap has, for the most part, been extrapolated from studies that were conducted outside of intimate relationship contexts (e.g., same-sex friendships). In addition, the gender differences that have been found in non-marital relationships are often small and inconsistent across studies (see Burleson, 2003).

Second, research evaluating the support gap hypothesis has generally failed to distinguish adequately between several components of the social support construct. An emerging consensus argues for the importance of distinguishing between support that is perceived to be available if needed (i.e., perceived support) and the actual supportive behaviors expressed during support interactions (i.e., support behaviors) (see Reis \& Collins, 2000). This distinction is important because the support behaviors that lead Person A to feel supported might have no impact at all-or even a negative impact-on Person B (Carels \& Baucom, 1999; Sarason, Sarason, \& Pierce, 1994; Verhofstadt, Buysse, Ickes, De Clercq, \& Peene, 2005). Previous studies investigating gender differences in supportive behavior or in perceived support have yielded some contrasting findings: Husbands report receiving more support (cf. support behaviors) from their wives than vice versa (Belle, 1982), whereas husbands and wives report equal levels of perceived spousal support (Xu \& Burleson, 2001).

Another issue concerns the distinction between emotional support (i.e., expressions of sympathy, concern, caring, and acceptance) and instrumental support (i.e., practical help, behavioral assistance) (see Wills \& Shinar, 2000). Although the available research findings seem to be consistent with the support gap hypothesis with regard to wives' greater provision of emotional support (Cutrona, 1996), they have not yet established whether men provide more instrumental support (Xu \& Burleson, 2001), as the support gap hypothesis presumes. 
Because the current social support literature conceptually and empirically differentiates support perceptions from support behaviors and differentiates emotional support from instrumental support, and because the discrepancies in the findings regarding gender differences in each support component have not been resolved at the present time (see Wills \& Shinar, 2000), a comprehensive study of gender differences in spousal support requires several types of measures (perceptions vs. behavior, emotional vs. instrumental).

Third, research addressing hypotheses about gender differences in social support has relied primarily on self-report methods. This is a problem to the extent that cognitive and motivational processes bias the reports of respondents who attempt to recall, interpret, and aggregate past experiences into current overall impressions (Schwarz, Groves, \& Schuman, 1998). In order to obtain a better understanding of support enactment processes and support perception processes, observational methods are required.

Although observational research is scarce because it is labor-intensive and timeconsuming, it appears to be essential in this area of research. Indeed, the little observational research that has been conducted using married couples has found no significant gender differences in spousal support behaviors, and these null findings directly challenge the marital support gap hypothesis (Pasch et al., 1997). Accordingly, the inconsistency between the findings from studies measuring spousal support via self-reports versus observational methods is currrently an important topic for research in this area.

Observational research is particularly useful for assessing the validity of spouses' ratings of perceived support. Spouses' ratings of perceived support in a particular relationship involves a synthesis of the details of past, present, and imagined future interactions into generalized expectations and impressions about that specific relationship (Hinde, 1997). This level of analysis should be clearly differentiated from that applying to feelings of support during a specific support episode, which is best captured through the use of observational 
research (Reis \& Collins, 2000). Because the details of real interaction matter, studying partners' perception of spousal support at the level of a single controlled supportive interaction may provide us with more immediate and behaviorally-based information about how husbands and wives differ in their experience of spousal social support.

Another limitation of previous studies is that between-gender differences were examined, whereas the relative frequencies of support behavior within-gender were not analyzed. For instance, in line with the widely held gender stereotypes, women should provide their male partners with more emotional support than instrumental support, whereas men should provide their female partners with more instrumental support than emotional support. However, one study that tested these "support gap" hypotheses found substantial parallels (i.e., similarity) between men's and women's profiles of support behaviors (Goldsmith \& Dun, 1997).

Finally, previous research has relied on statistical significance as the sole criterion for the interpretation of gender differences, thereby failing to assess the magnitude of gender differences -i.e., their effect size. Researchers have generally overlooked the substantial overlap between the behavior of men and women and have misrepresented small differences as strongly distinguishing the two genders when they are actually quite similar (Aries, 1996).

In sum, a great deal of caution must be exercised in drawing inferences from data about gender differences in spousal support. Instead of accepting the marital "support gap" as an article of faith, we should re-examine it in research that deals with the limitations of the previously reviewed studies. The present research aimed to conduct a more rigorous test of the marital support gap hypotheses by improving upon the previous research in at least four ways. First, we tested the support gap hypotheses within samples of committed couples, rather than in samples of same-sex male and female friends. Second, we tested to see if husbands and wives differ in their levels of perceived support as well as in their actual exchange of 
spousal support (i.e., support behaviors). Specifically, we analyzed gender differences in positive and negative classes of support solicitation and provision behavior, including emotional as well as instrumental types of support. Third, we used a combination of selfreport and observational methods in our research. Specifically, we tested for gender differences in (a) support behavior and perceived support, as assessed via global self-reports (Study 1 and 2), and in (b) observed support behaviors and interaction-based perceived support (i.e., so-called on-line perceived support), as assessed during specific support transactions (Study 2). Fourth, we analyzed both between and within-gender differences in spousal support, and we computed and reported the relevant effect sizes in all cases.

\section{Study 1}

\section{Method}

Participants The sample consisted of 458 committed, heterosexual couples whose participation was solicited by using a snowball sampling method. Research assistants contacted people by telephone and gave a short, standardized description of the research (e.g., its inclusion criteria, aims, and procedure). To participate, the couples had to have been involved in their heterosexual relationship for at least one year, and they had to have been married for at least six months. All couples who participated in the study did so voluntarily. The demographic characteristics of the participants are reported in Table 1.

\section{INSERT TABLE 1 ABOUT HERE}

Procedure ${ }^{l}$ During the first telephone contact, a home-visit was scheduled for the eligible couples who expressed interest in the study to complete a package of questionnaires. The research assistant who met with the couple in their home remained present during the questionnaire completion to answer any questions and to prohibit the partners from conversing or sharing their responses. After both partners had completed the questionnaires, the couples were debriefed more fully about the global aim of the study and thanked for their 
participation. The couples were assured that their data would be analyzed anonymously and confidentially, and they were asked to grant written permission to allow the researchers to use their data for scientific purposes.

\section{Measures}

Support behaviors. The behavioral features of spouses' supportive transactions were assessed by a questionnaire based on the Social Support Interaction Coding System (Bradbury $\&$ Pasch, 1994). ${ }^{2}$ The social support interaction questionnaire (SSIQ; Verhofstadt, Buysse, \& Rosseel, 2005) included 54 items, and each item was rated on a 9-point Likert scale $(1=$ very unlikely, $9=$ very likely). Five subscales assessed the likelihood of (a) positive help-seeker behavior (e.g., gives clear analysis of problem, recognizes partner as an aid, agrees with suggestions of helper), (b) negative help-seeker behavior (e.g., rejects help, criticizes helper, makes demands for support), (c) positive emotional helper behavior (e.g., reassurance, expression of care for help-seeker, understanding), (d) positive instrumental helper behavior (e.g., offers specific plan or assistance), and (e) negative helper behavior (e.g., criticizes, minimizes problem).

Subscale scores were computed separately for the husbands and the wives by computing the mean of their responses across all items in the scale. Cronbach's alphas were adequate to good (ranging from .73 and .87 for the husbands, and from .76 and .85 for the wives), indicating acceptable internal consistency for all five subscales.

Perceived support. The QRI support-scale (Pierce, Sarason, \& Sarason, 1991; Verhofstadt, Buysse, Rosseel, \& Peene, in press) was used to assess the level of support participants perceive to be available from their spouse. The items on this measure were each rated on a 4-point Likert scale $(1=$ not at all, $4=$ very $m u c h)$, and the spouses' total scale scores were obtained by computing the mean of their responses across all items in the scale. 
The alpha reliabilities for the perceived support scales used in this study were high $(\alpha=.84$ for the husbands, and $\alpha=.82$ for the wives).

\section{Results}

Support Behaviors To examine gender differences in spouses' global reports of support behaviors, a repeated measures MANOVA was conducted with gender entered as a withincouples factor. The analysis revealed a significant multivariate effect of gender on spouses' support behaviors, Wilks's lambda $=.77, F(5,453)=26.94, p<.001$. Further univariate repeated measures $F$-tests revealed a significant gender difference for each of the support behaviors separately. The means, standard deviations, univariate $F$-values for the various behaviors as a function of gender, and the respective effect sizes are reported in Table 2.

\section{INSERT TABLE 2 ABOUT HERE}

The participants reported that the wives display more positive support seeking behavior, $F(1,457)=48.48, p<.001$, and more negative support seeking behavior, $F(1,457)$ $=100.49, p<.001$, than their husbands. The wives were also seen as providing more emotional support, $F(1,457)=15.84, p<.001$, and more instrumental support, $F(1,457)=$ $5.09, p<.05$, to their husbands than vice versa. Finally, the husbands were seen as being more negative than their wives when the husbands were in the helper role, $F(1,457)=9.03, p<.01$.

To examine the profiles of husbands' and wives' support behaviors within the role of helper or within the role of helpee (i.e., the within-gender differences in the support behaviors within a given role), we conducted planned contrasts using paired $t$-tests to compare the positive and negative behaviors within each role. The results of these analyses revealed that, when they were rated in the helpee role, both the husbands, $t(458)=36.14, p<.001$, and the wives, $t(458)=34.80, p<.001$, were more likely to report positive behavior than negative behavior. 
In addition, when they were rated in the helper role, the husbands were seen as displaying more positive than negative behavior for positive emotional support, $t(458)=$ $37.63, p<.001$, and for positive instrumental support, $t(458)=38.52, p<.001$. A similar pattern of results was found for the wives in the helper role for both positive emotional support, $t(458)=42.98, p<.001$, and for positive instrumental support, $t(458)=43.12, p<$ .001 . Finally, husbands, $t(458)=5.44, p<.001$, as well as wives, $t(458)=6.80, p<.001$, were both rated as providing more emotional than instrumental support.

Perceived Support To test for gender differences in perceived support, a repeated measures ANOVA was performed with gender entered as a within-couples factor. As indicated in Table 2, global ratings of perceived spousal support did not differ between husbands and wives, $F(1$, $457)=0.02, n s$, indicating that the husbands and wives felt equally supported by their spouse.

\section{Discussion}

Consistent with the support gap hypothesis in marriage, the results of Study 1 revealed significant gender differences in self-reported support soliciting and provision. In general, wives were rated as providing more emotional and instrumental support than they received, and wives were rated as responding in a less negative way when their spouse requested help than their husbands do. However, the average effect size of these gender differences was small - using $\eta_{p}^{2}$-values of .01, .10,.25 as thresholds to define small, medium, and large effects (Cohen, 1988). Furthermore, our results indicated that the support gap hypothesis does not seem to apply to the overall perception of marital support, with husbands and wives reporting equal levels of perceived spousal social support.

Of further interest was that the husbands' and wives' profiles of support behaviors showed strong similarities. For example, although men seem to respond more negatively to their wife when she is asking for support than vice versa, positive responses when providing support are still more prevalent than negative responses for both husbands and wives. 
In summary, then, the evidence for the hypothesized marital support gap in Study 1 takes the form of a few relevant differences with small effect sizes that must be viewed against the backdrop of substantial similarity between the husbands and wives who were tested in this study.

Study 2 was designed to replicate and extend the findings of Study 1. First, we wanted to see if the Study 1 findings were robust. The finding that both spouses reported a greater use of positive as well as negative support-seeking behavior by wives than by husbands seems somewhat contradictory with respect to the marital support gap hypothesis, and therefore requires replication. Second, and of greater importance, we wanted to see if there is evidence for the hypothesized marital support gap within the context of actual support transactions, by using observational measures of support behavior and by using measures of on-line perceived support.

Study 2

Method

Participants The sample consisted of 32 committed heterosexual couples. Advertisements were placed in magazines and newspapers recruiting couples who were willing to participate in a research project on close relationships. The couples who responded positively to the recruitment ads were given a standard description of the project and were evaluated for their eligibility to participate. To participate, the members of each couple had to have been involved in their heterosexual relationship for at least one year, and to have been married for at least six months. The eligible couples who expressed interest in participating in the study were scheduled to attend a laboratory session. Demographic characteristics of these participants are reported in Table 1. 
Procedure ${ }^{1}$ After providing their informed consent, the participants completed a set of questionnaires, including the SSIQ and the QRI.

Interaction session. We refer the reader to Verhofstadt, Buysse, Ickes, De Clercq, \& Peene (2005) for a detailed description of this part of the procedure. The participants were led into a laboratory that was furnished as a living room, and was equipped so that the couple's interaction could be videotaped with their prior knowledge. Following the procedure used in previous observational research on social support in marriage, the spouses were asked to discuss a salient personal problem that was formally designated as being either the man's or the woman's problem. To ensure sufficient variability, the gender of the support seeker (man vs. woman) was systematically counterbalanced (see also Verhofstadt, Buysse, De Clercq, \& Goodwin, 2005). When both partners had agreed to discuss the issue, they were instructed to try to act much as they would at home when discussing an important marital or personal problem with each other. The partners were allowed to interact as long as they considered necessary, up to a maximum time limit of 30 minutes.

Video review procedure. Immediately after their interaction had been recorded, the partners were seated separately and asked to complete a video-review task (e.g., Fletcher \& Thomas, 2000; Sillars, Roberts, Leonard, \& Dun, 2000; Simpson, Ickes, \& Blackstone, 1995). The partners were asked to imagine living through and re-experiencing their interaction again while they each viewed a videotaped copy of the interaction.

At random yet regular points of time, the videotape paused automatically and the participants were instructed to report their on-line perception of being supported by their partner at that specific point of time in the interaction. This computerized procedure served the purpose of selecting several random time samples $(M=17)$ from the interaction during which some form of spousal support was presumably given and received (see De Clercq, Buysse, Roeyers, Ickes, Ponnet \& Verhofstadt, 2001). These time samples were defined as the 
3-second intervals immediately before the computer paused the videotaped interaction. At the end of the session, the members of each couple were fully debriefed.

Measures

Support behaviors. See Study 1 for a description of this measure. The Cronbach's alphas ranged between .68 and .94 for the husbands, and between .68 and .93 for the wives.

Perceived support. See Study 1 for a description of this measure. Cronbach's alpha was .80 for the husbands and .82 for the wives.

Observed support behaviors. The behavioral data were coded by means of the Social Support Interaction Coding System (SSICS, Bradbury \& Pasch, 1994), a system that was specifically developed for coding the support solicitation and provision behavior of partners during discussions of personal, non-marital difficulties. We used five SSICS categories to assess (a) positive help-seeker behavior (e.g., gives clear analysis of problem, recognizes partner as an aid, agrees with suggestions of helper), (b) negative help-seeker behavior (e.g., rejects help, criticizes helper, makes demand for support), (c) positive emotional helper behavior (e.g., reassurance, expression of care for help-seeker, understanding), (d) positive instrumental helper behavior (e.g., offers specific plan or assistance), and (e) negative helper behavior (e.g., criticizes, minimizes problem).

Applying the same computerized procedure as during the video-review task, the behavioral data were independently coded by two trained observers. While each observer watched the couple's videotaped interaction, the computer program paused the videotape at exactly the same moments in the interaction as during the video-review task. Our trained observers then coded the behaviors that occurred during the 3-second time samples that immediately preceded each tape stop during the video-review task. Using the behavioral cues that were available during each time sample, the trained observers coded for the presence or 
absence of each behavioral category included in the present study. Each time sample could potentially include none, one, or some of these behaviors.

A male and a female clinical psychologist were trained as the data coders. They were told only who was the support seeker (man vs. woman), and were kept "blind" with respect to all of the other variables being studied. The coders separately coded the behavior of each partner in each interaction, alternating between the man's and woman's behavior. The interobserver kappas indicated good levels of interobserver reliability $\left(\kappa_{\text {range }}=.60-.92\right.$; Fleiss, 1981).

The measures derived from our observer coding were computed as follows. We reduced the coding of each behavioral category obtained for each time sample to the percentage of behavior displayed during the interaction, using the number of times the behavioral category was present as the numerator and the total number of time samples during the entire interaction as the denominator. This percentage-of-behavior index was used in the analyses reported below. It reflects how frequently a particular behavior was displayed during the total number of time samples selected in the interaction.

On-line perceived support. On-line perceived support was assessed by means of a 7point rating scale $(1=$ not at all, and $7=$ very $m u c h)$ on which the partners indicated the extent to which they felt helped and supported during the interaction. For each participant, the on-line scores were averaged across the time samples ( $\alpha=.86$ for husbands, and $\alpha=.90$ for wives). This score reflected the participants' experience of being supported during the interaction.

\section{Results}

Support Behaviors To test for gender differences in spouses' global reports of support behaviors, a MANOVA was conducted with gender entered as a between-couples factor. ${ }^{3}$ The results of this analysis revealed a significant multivariate gender effect, Wilks's lambda $=.40$, 
$F(5,26)=7.90, p<.001$. Further univariate analyses revealed a significant main effect for gender on each of the separate behaviors. ${ }^{4}$ Table 3 reports the means and standard deviations for each behavior by gender, along with the significant one-way ANOVA $F$-ratios and effect sizes.

\section{INSERT TABLE 3 ABOUT HERE}

As in Study 1, univariate $F$-tests showed that wives seemed to display more positive support seeking behavior, $F(1,30)=8.86, p<.01$, more negative support seeking behavior, $F(1,30)=11.03, p<.01$, and more emotional support, $F(1,30)=3.50, p<.10$, than their husbands. Also in line with the Study 1 results, husbands were significantly more negative in providing support than their wives, $F(1,30)=3.79, p<.10$. Contrary to the results of Study 1 , however, the husbands and the wives did not differ in the amount of instrumental support they provided, $F(1,30)=0.14$, ns. The sizes of the significant effects in this study ranged from small to large (Cohen, 1988).

To examine the husbands' and the wives' behavioral profiles within the role of helper or within the role of helpee (i.e., the within-gender differences in the support behaviors within a given role), we conducted planned contrasts using paired $t$-tests to compare the positivity and negativity of the various support behaviors. As in Study 1, the results of these comparisons revealed that, when they were in the helpee role, both the husbands, $t(15)=$ $10.39, p<.001$, and the wives, $t(15)=9.28, p<.001$, were seen as displaying more positive than negative behavior.

In addition, when they were in the helper role, the husbands were seen as displaying more positive than negative behavior for positive emotional support, $t(15)=10.16, p<.001$, and for positive instrumental support, $t(15)=11.07, p<.001$. A similar pattern of results was found for wives in the helper role for positive emotional support, $t(15)=16.01, p<.001$, and for positive instrumental support, $t(15)=13.71, p<.001$. 
Finally, the wives, $t(458)=6.89, p<.001$, but not the husbands, $t(15)=0.84, n s$, were perceived as providing more emotional support than instrumental support, consistent with the only asymmetry predicted by the marital support gap hypothesis that has received fairly consistent support in previous research..

Perceived Support To test for gender differences in perceived support, a repeated measures ANOVA was performed with gender entered as a within-couples factor (see Table 3). As in Study 1, the results of this ANOVA revealed that husbands and wives did not differ in their global ratings of perceived support, $F(1,31)=0.91, n s$, indicating that the husbands and the wives felt equally supported by their spouse.

Observed Support Behaviors To test for gender differences in the observed support behaviors that were coded by the trained raters in Study 2, a MANOVA was conducted with gender entered as a between-couples factor. The results of this multivariate analysis revealed no significant result, Wilks's lambda $=.87, F(5,26)=0.81, n s$. The means, standard deviations, univariate $F$-values for the various observed support behaviors as a function of gender, and their effect size are reported in Table 4. As these data reveal, the relative amounts of observed support solicitation and provision behaviors were very similar for the husbands and the wives.

\section{INSERT TABLE 4 ABOUT HERE}

To examine the husbands' and the wives' behavioral profiles within the role of helper or within the role of helpee (i.e., the within-gender differences in the support behaviours within a given role), we conducted planned comparisons using paired $t$-tests to compare the positivity and negativity of the various support behaviors. Again, the results of these analyses showed that both the husbands and the wives exhibited more positive than negative classes of behavior when seeking support, $t(16)=14.64, p<.001$ and $t(15)=14.15, p<.001$, respectively. The husbands were more likely to display positive than negative behavior when providing positive emotional support, $t(15)=8.57, p<.001$, and positive instrumental 
support, $t(15)=2.76, p<.05$. A similar pattern of results was found for wives when providing positive emotional support, $t(15)=6.26, p<.001$, and positive instrumental support. $t(15)=$ 2.41, $p<.05$. Finally, both the husbands, $t(15)=7.19, p<.001$, and the wives, $t(15)=6.60$, $p<.001$, provided more emotional than instrumental support to their partner.

On-line Perceived Support To test for gender differences in on-line perceived support, an ANOVA was performed with gender entered as a between-couples factor. As indicated in Table 4, the results of this ANOVA revealed that husbands and wives did not differ in their level of perceived support, as assessed during actual support transactions, $F(1,30)=0.06, n s$.

\section{Discussion}

The portion of the Study 2 results that were based on self-reports largely replicated the self-report findings of Study 1. Similar to our Study 1 results, we found consistent gender differences in global reports of support behavior, with the wives rated as receiving less emotional and instrumental support from their male partners than they are providing to them. Also as in Study 1, both spouses agreed that husbands are more likely to provide negative types of support than their wives do. Exclusive of the effect sizes for self-reported helpee behaviors, the effect sizes due to gender differences were-as in Study 1-small.

Of particular interest in Study 2 was the test of gender differences in observed spousal support behaviors. Contrary to the support gap hypothesis and contrary to our findings regarding self-reported support, the behavioral data did not yield any significant gender differences favoring women in frequency of emotional and instrumental support. Furthermore, we found evidence that both genders engaged in the same amount of negative behavior when exchanging social support. In sum, our observational data fail to offer any evidence for the support gap hypothesis. These null findings are, however, consistent with the lack of gender differences reported in previous research in which observation measures of support behaviors were coded during actual support exchanges (Pasch et al., 1997). 
As in Study 1, husbands and wives reported similar patterns of support behaviors during support transactions. Similar to our findings based on self-reported social support, our observational data indicated that the relative frequency of observed support behaviors within husbands and wives was substantially similar. Specifically, both our self-report and our observational data indicated that husbands and wives seem to communicate in a more positive than negative way when providing and soliciting support.

As in Study 1, no differences were found between husbands and wives in their global reports of support that they perceive within their marriage. Our findings concerning spouses' interaction-based judgments of support were similar in this regard: husbands and wives felt equally supported by their spouse when seeking support, as assessed during a specific supportive interaction.

\section{General Discussion \\ Summary of Results}

The present studies complement and extend previous research on gender differences in spousal support by (a) using samples of committed couples, (b) examining multiple aspects of social support, (c) using self-report and observational methods, and (d) analyzing between and within-gender differences.

The data from the current investigation provide mixed support for the hypothesized marital support gap in actual support behaviors. Global self-report measures indicated that, in both studies, there were a few significant differences between husbands and wives, in their helpee as well as their helper behavior. Specifically, the wives were perceived as providing both more emotional support and more instrumental support than their husbands. In addition, the husbands were described as being more negative support providers than their wives. These findings regarding global reports of support behavior are consistent with the claim that women receive less support and the support they receive is less helpful than what they provide 
to their husbands. Spouses' reports of how they ask and provide support to each other seem to be consistent with the belief that the support gap between men and women exists in marital relationships as well as in less intimate relationships.

It is also noteworthy that wives are described as displaying higher levels of both positive and negative support-seeking behavior than their husbands. These results are clearly in line with the female stereotype that wives depend more on others for help or rescue than men do (Cutrona, 1996). It is also noteworthy that similar findings have emerged in studies conducted outside of the marital relationship, in which women report seeking support more often when coping with stressful events, and feeling more comfortable asking for help than men do (e.g., Thoits, 1991).

On the other hand, in sharp contrast to the support gap hypothesis, the results based on observed support behaviors revealed no significant differences between husbands and wives (Study 2). In that respect, our findings are in accord with earlier observational research by Pasch et al. (1997). The inconsistency between the results derived from self-report versus observational methods supports the claim that there are gender differences in how spouses say that they behave, whereas husbands and wives do not necessarily differ when social support is investigated directly (Pasch et al., 1997).

One possible reason for this discrepancy is that self-reports of recalled behavior may be biased by sex role stereotypes. According to this interpretation, widely held stereotypes about the interaction styles of men and women shape our perception of gender differences in social support, making them greater than the behavioral differences actually are (see Aries, 1996). Another possible reason for this discrepancy is that gender differences in social support may be so subtle that they are often not significant when studied within a single support exchange episode. However, when participants are asked to mentally aggregate across 
such episodes when providing self-report measures of social support, they might be able to perceive such subtle differences and report them accurately.

In any event, because the observational results stand in such sharp contrast with the gender differences found for self-reported support behavior, we assessed the correspondence between both types of measures of support behaviors by means of correlational analyses. And, with only one major exception, we found that the self-reported behaviors were not significantly associated with the observed behaviors. The relevant correlations were as follows: $r=.10, n s$. for positive seeking, $r=.51, p<.01$ for negative seeking, $r=.10, n s$. for emotional support, $r=-.17, n s$. for instrumental support; and $r=.05, n s$. for negative support provision.

These data indicate that a considerable amount of variability in the observational measures was not explained by the self-report measures of support behaviors, and vice versa. In light of the low correspondence between both methods, it is reasonable to assume that both methods pertain to distinct psychological constructs and therefore provide unique - and sometimes inconsistent - information. Self-reports give insight in how supportive one thinks he or she is, whereas observational measures provide more objective information. These results do not necessarily imply that self-reports are no valid option for measuring supportive behaviors. Moreover, one might argue that spouses' reality is what husbands and wives perceive, and that they reflect upon their reality and respond in kind to those perceptions. In accord with previous work by Xu and Burleson (2001), the current results do not conform to the view of an existing support gap for perceived spousal support. Although the wives in our studied seemed to receive less emotional support, less instrumental support, and more negative support from their husbands than vice versa, these wives did not feel less supported by their husbands than their husbands felt supported by them. Future research on the differences between men and women in the degree of support they actually receive from 
their spouse (i.e., actual support), the level of support that they would like to receive from their partner (i.e., desired support), or the discrepancy between both (i.e., support satisfaction) is needed to help resolve the apparent paradox implied by these findings.

A comparison of the profiles of men's and women's support behaviors revealed a high degree of similarity in their pattern of responses during social support interactions. This high level of similarity was consistent across both studies and across both the self-report and the observational methods. Moreover, this high level of similarity has also been reported in the only previous study that has directly addressed this issue (Goldsmith \& Dun, 1997). This strong evidence of similarity is, however, at odds with the gender stereotype that men and women differ in the types of social support they provide to distressed others. Although women are expected to be more likely to respond to another person's disclosure of a problem by providing emotional support, whereas men are expected to be more instrumentally oriented and less comfortable with an expressive role, our results indicate that emotional responses are more frequent in both men and women than instrumental responses are.

\section{Future Research}

The present research suggests a number of directions for future research. First, the present findings emphasize the importance of a multi-component approach when evaluating and interpreting gender differences in spousal support. Future research should be conducted to replicate these findings and to further specify the types of data (e.g., self-report vs. observational measures, support perceptions vs. support behaviors) to which the support gap hypothesis does and does not apply. Second, in light of the discrepancy between self-reported and observed spousal support in the present research, both methods should be routinely used in future research to provide a more detailed and comprehensive picture of gender differences in marriage. Finally, future studies should also investigate gender differences in behavior 
across a range of situations, because an important limitation of the present study was that we did not attempt to examine the situational variability in spouses' support behavior.

\section{Conclusions and Implications}

How can we evaluate and interpret the present findings? If we look at the statistical significance of our results, there appear to be differences between husbands and wives in selfreported support behavior, in combination with striking similarities between husbands and wives in perceived spousal support, in observed support behavior, and in behavioral profiles. These findings lead us to our first conclusion: That a few gender differences in spousal support have been detected, but that they are situated within the context of many striking similarities.

When we examine the magnitude of the differences in self-reported support behavior, we see that the effect sizes averaged across our studies range from small to moderate and that the overall effect size due to gender differences only approaches the moderate range. Specifically, the gender differences accounted for less than $6 \%$ of the variance at best and generally less than $1 \%$ of the variance in self-reported support behavior. Thus, when we look beyond statistical significance and focus on effect size or percent of variance explained, our findings suggest that the overlap in self-reported support behavior of husbands and wives is indeed highly substantial. This observation leads us to our second major conclusion: That, apart from those men and women who fall at the extreme ends of the distribution and thereby confirming existing gender stereotypes, there are sizable numbers of both men and women that resemble prototypical exemplars of the opposite gender in terms of supportive behavior (Aries, 1996; Fletcher, 2002).

Viewed collectively, our findings are not consistent with the popular polarized conceptions of husbands and wives in support transactions. Our findings rather coincide with the view advocated by relationship researchers that men and women are far more similar than 
different in how they communicate and attempt to support each other in their personal relationships (e.g., Canary \& Dindia, 1998; Canary \& Emmers-Sommer, 1997).

We are convinced that the study of gender differences in spousal support is important for achieving a nuanced understanding of the dynamics of this important aspect of marital relationships. However, as previously advocated by Wood and Dindia (1998), we do not want to overemphasize gender differences because the construction of polarized conceptions of men and women in interaction fosters falsely dichotomous thinking, and risks reinforcing gender stereotypes that fuel divisions between women and men. Instead, we wish to underscore the importance of continuing our empirical search for gender differences in spousal support, but only in the context of being fully aware of, and fully appreciative of, the many similarities between the genders. 


\section{References}

Aries, E. (1996). Men and women in interaction: Reconsidering the differences. New York, NY: Oxford University Press.

Belle, D. (1982). The stress of caring: women as providers of social support. In L. Goldberger \& S. Breznitz (Eds.), Handbook of stress: Theoretical and clinical aspects (pp. 496505). New York, NY: Free Press.

Bradbury, T. N., \& Pasch, L. A. (1994). The Social Support Interaction Coding System (SSICS). Unpublished coding manual, University of California, Los Angeles.

Burleson, B. R. (2003). The experience and effects of emotional support: What the study of cultural and gender differences can tell us about close relationships, emotion, and interpersonal communication. Personal Relationships, 10, 1-23.

Canary, D. J., \& Dindia, K. (1998). Sex differences and similarities in communication. Mahwah, NJ: Erlbaum.

Canary, D. J, \& Emmers-Sommer, T. M. (1997). Sex and gender differences in personal relationships. New York, NY: Guilford.

Carels, R. A., \& Baucom, D. H. (1999). Support in marriage: Factors associated with on-line perceptions of support helpfulness. Journal of Family Psychology, 13(2), 131-144.

Cohen, J. (1988). Statistical power analysis for the behavioral sciences $\left(2^{\text {nd }}\right.$ ed.). Hillsdale, NJ: Erlbaum.

Cohen, S., Gottlieb, B. H., \& Underwood, L. G. (2000). Social relationships and health. In S. Cohen, B. H. Gottlieb, \& L. G. Underwood (Eds.), Social support measurement and intervention: A guide for health and social scientists (pp. 3-28). New York: Oxford University Press.

Cutrona, C. E. (1996). Social support in couples. Thousand Oaks, CA: Sage. 
De Clercq, A., Buysse, A., Roeyers, H., Ickes, W., Ponnet, K., \& Verhofstadt, L. L. (2001). VIDANN: A video annotation system. Behavior Research Methods, Instruments and Computers. 33(2), 159-166.

Fleiss, J. L. (1981). Statistical methods for rates and proportions. New York : Wiley.

Fletcher, G. J. O. (2002). The new science of intimate relationships. Malden, MA: Blackwell.

Fletcher, G. J. O., \& Thomas, G. (2000). Behavior and on-line cognition in marital interaction. Personal Relationships, 7, 111-130.

Goldsmith, D. J., \& Dun, S. A. (1997). Sex differences and similarities in the communication of social support, Journal of Social and Personal Relationships, 14(3), 317-337.

Hinde, R. (1997). Relationships: A dialectical perspective. East Sussex, England: Psychology Press.

Pasch, L. A., \& Bradbury, T. N. (1998). Social support, conflict, and the development of marital dysfunction. Journal of Consulting and Clinical Psychology, 66(2), 219-230.

Pasch, L. A., Bradbury, T. N., \& Davila, J. (1997). Gender, negative affectivity, and observed social support behavior in marital interaction. Personal Relationships, 4(4), 361-378.

Pierce, G. R., Sarason, I. G., \& Sarason, B. R. (1991). General and relationship-based perceptions of social support: Are two constructs better than one? Journal of Personality and Social Psychology, 61(6), 1028-1039.

Reis, H. T., \& Collins, N. (2000). Measuring relationship properties and interactions relevant to social support. In S. Cohen, L. G. Underwood, \& B. H. Gottlieb (Eds.), Social support measurement and intervention: A guide for health and social scientists (pp. 136-194). New York: Oxford University Press.

Sarason, I. G., Sarason, B. R., \& Pierce, G. R. (1994). Social support: Global and relationshipbased levels of analysis. Journal of Social and Personal Relationships, 11, 295-312. 
Schwartz, N., Groves, R. M., \& Schuman, H. (1998). Survey methods. In D. T. Gilbert, S. Fiske, \& G. Lindzey (Eds.), The handbook of social psychology, $4^{\text {th }}$ ed., vol. 2 (pp. 143179). Boston, McGraw-Hill.

Sillars, A., Roberts, L. J., Leonard, K. E., \& Dun, T. (2000). Cognition during marital conflict: The relationship between thought and talk. Journal of Social and Personal relationships, 17(6), 479-502.

Simpson, J., Ickes, W., \& Blackstone, T. (1995). When the head protects the heart: Empathic accuracy in dating relationships. Journal of Personality and Social Psychology, 69, 629-641.

Steil, J. M. (2000). Contemporary marriage: Still an unequal partnership. In C. Hendrick \& S. S. Hendrick (Eds.), Close relationships: A sourcebook (pp. 124-136). Thousand Oaks, CA: Sage.

Tannen, D. (1990). You just don't understand: Men and women in conversation. New York, NY: Ballentine Books.

Thoits, P. A. (1991). Gender differences in coping with emotional distress. In J. Eckenrode (Ed.), The social context of coping (pp. 107-138). New York, NY: Plenum Press.

Verhofstadt, L. L., Buysse, A., De Clercq, A., \& Goodwin, R. (2005). Emotional arousal and negative affect in marital conflict: The influence of gender, conflict structure, and demand-withdrawal. European Journal of Social Psychology, 35, 449-467.

Verhofstadt, L. L., Buysse, A., Ickes, W., De Clercq, A., \& Peene, O. J. (2005). Conflict and support interactions in marriage: An analysis of couples' interactive behavior and online cognition. Personal Relationships, 12(1), 23-42.

Verhofstadt, L. L., Buysse, A., \& Rosseel, Y. (2005). Conflict and Support in Close Relationships: An Investigation of Couples' Behavioral Profiles. Manuscript submitted for publication. 
Verhofstadt, L. L., Buysse, A., Rosseel, Y., \& Peene, O. J. (in press). Confirming the threefactor structure of the Quality of Relationships Inventory within couples. Manuscript accepted for publication in Psychological Assessment.

Wills, T. A., \& Shinar, O. (2000). Measuring perceived and received social support. In S. Cohen, L. G. Underwood, \& B. H. Gottlieb (Eds.), Social support measurement and intervention: A guide for health and social scientists (pp. 86-135). New York: Oxford University Press.

Wood J. T., \& Dindia, K. (1998). What's the difference? A dialogue about differences and similarities between women and men. In D. J. Canary \& K. Dindia (Eds.), Sex differences and similarities in communication (pp. 19-39). Mahwah, NJ: Lawrence Erlbaum Associates.

Xu, Y., \& Burleson, B. R. (2001). Effects of sex, culture, and support type on perceptions of spousal social support : An assessment of the «Support Gap » hypothesis in early marriage. Human Communication Research, 27(4), 535-566. 


\section{Author Note}

Lesley L. Verhofstadt, Ann Buysse, and Kim G. De Corte, Department of Experimental Clinical and Health Psychology, Ghent University, Ghent, Belgium.

William Ickes, Department of Psychology, University of Texas at Arlington, Arlington, Texas, USA.

Lesley Verhofstadt is supported by the Fund for Scientific Research, Flanders (Belgium).

Correspondence concerning this article should be addressed to Lesley L. Verhofstadt, Department of Experimental Clinical and Health Psychology, Ghent University, H.

Dunantlaan 2, B-9000 Ghent, Belgium, Tel: $+32-9-264.91 .44$, Fax: +32 - 9-264.64.89, E-mail: lesley.verhofstadt@ugent.be 


\section{Footnotes}

${ }^{1}$ Ethical procedures were followed in accordance with American Psychological Association guidelines.

${ }^{2}$ This questionnaire assessed the respondents' own behaviors (i.e., self-reported) as well as their partner's behaviors (i.e., partner-reported). The self-reported and partnerreported scores for support solicitation and provision behaviors were significantly correlated, and their mean scores did not differ significantly. Therefore, we computed a score for all support behaviors reported in the present studies by averaging the self-reported and partnerreported scores.

${ }^{3}$ In Study 1, we collected self-reported behavioral data for each spouse in both the helpee $(n=458)$ and helper $(n=458)$ role. In Study 2, each spouse within a couple was randomly assigned to take either the helpee $(n=16)$ or the helper $(n=16)$ role; therefore we obtained self-reported and observed behavioral data for each spouse in either the helpee or the helper role, therefore requiring that we test for gender differences by treating gender as a between-dyads, rather than a within-dyads, variable.

${ }^{4}$ Because of the small sample size in Study 2, the marginally significant effects $(p<$ .10) found for emotional and negative support provision were also interpreted. 
Table 1

Sample Characteristics for Study 1 and Study 2

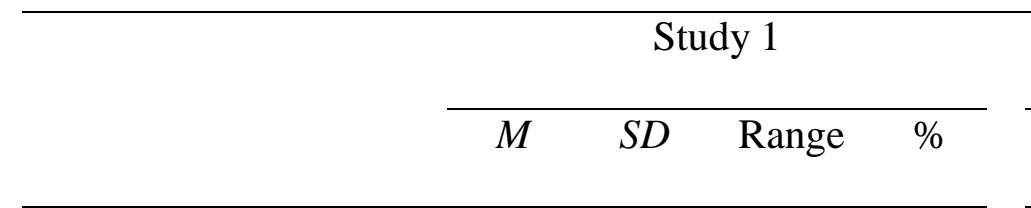

Study 2

Age (in years)

Men

$42.34 \quad 11.91 \quad 22-78$

$39.12 \quad 11.04 \quad 27-72$

Women

$39.58 \quad 12.12 \quad 19-78$

$37.03 \quad 10.51 \quad 23-61$

Education (in years)
Men
$14.09 \quad 2.61 \quad 6-17$
$15.66 \quad 1.98 \quad 6-17$
Women
$14.18 \quad 2.64 \quad 6-17$
$15.69 \quad 1.86 \quad 12-17$

Relationship Duration

(in years)

$11.15 \quad 11.17 \quad 1-55$

$\begin{array}{lll}7.81 & 9.26 & 1-31\end{array}$

Number of children

$1.50 \quad 1.30 \quad 0-5$

$1.09 \quad 1.23 \quad 0-4$

Professional activities

White collar worker

Men

Women

$57 \%$

$50 \%$

Blue collar worker

Men

$19 \%$

$3 \%$

Women

$8 \%$

$10 \%$

Other

Men

$36 \%$

$44 \%$

Women

$35 \%$

$40 \%$ 
Table 2

Means and Standard Deviations for Self-reported Support Behavior and Perceived Support (Study 1)

$$
\text { Men }(n=458) \quad \text { Women }(n=458)
$$

$\begin{array}{lllll}M & S D & & & \\ M & S D \quad F(1,457) & \eta_{p}^{2}\end{array}$

Helpee behavior $^{1}$

$\begin{array}{lllllll}\text { Positive } & 6.13 & 1.33 & 6.53 & 1.20 & 48.48 * * * & .10 \\ \text { Negative } & 3.01 & 1.08 & 3.49 & 1.17 & 100.49 * * * & .18\end{array}$

Helper behavior ${ }^{1}$

$\begin{array}{lllllll}\text { Emotional } & 6.77 & 1.36 & 6.95 & 1.26 & 15.84 * * * & .03 \\ \text { Instrumental } & 6.55 & 1.29 & 6.67 & 1.24 & 5.09 * & .01 \\ \text { Negative } & 3.09 & 1.00 & 2.99 & 0.98 & 9.03 * * & .02\end{array}$

$\begin{array}{lllllll}\text { Perceived support }^{2} & 3.31 & 0.51 & 3.31 & 0.52 & 0.02 & .00\end{array}$

\footnotetext{
${ }^{1}$ rated on 9-point scales $(1=$ very unlikely, $9=$ very likely $)$.

${ }^{2}$ rated on a 4-point scale $(1=$ not at all, $4=$ very much $)$.

$* p<.05, * * p<.01, * * * p<.001$ (two-tailed).
} 
Table 3

Means and Standard Deviations for Self-reported Support Behavior and Perceived Support (Study 2)

\begin{tabular}{llllll} 
Men $(n=16)$ & & \multicolumn{3}{l}{ Women $(n=16)$} \\
& $S D$ & $M$ & $S D$ & $F(1,30)$ & $\eta_{p}^{2}$
\end{tabular}

\begin{tabular}{|c|c|c|c|c|c|c|}
\hline \multicolumn{7}{|l|}{ Helpee behavior $^{1}$} \\
\hline Positive & 5.97 & 0.61 & 6.66 & 0.70 & $8.86^{* *}$ & .23 \\
\hline Negative & 3.12 & 0.72 & 4.05 & 0.86 & $11.03 * *$ & .27 \\
\hline \multicolumn{7}{|l|}{ Helper behavior ${ }^{1}$} \\
\hline Emotional & 6.64 & 0.75 & 7.12 & 0.71 & $3.50 *$ & .10 \\
\hline Instrumental & 6.55 & 0.60 & 6.64 & 0.74 & 0.14 & .00 \\
\hline Negative & 3.52 & 0.70 & 3.12 & 0.45 & $3.79 *$ & .11 \\
\hline Perceived support $^{2}$ & 3.58 & 0.35 & 3.51 & 0.40 & 0.91 & .03 \\
\hline
\end{tabular}


Table 4

Means and Standard Deviations for Observed Support Behavior and On-line Perceived Support (Study 2)

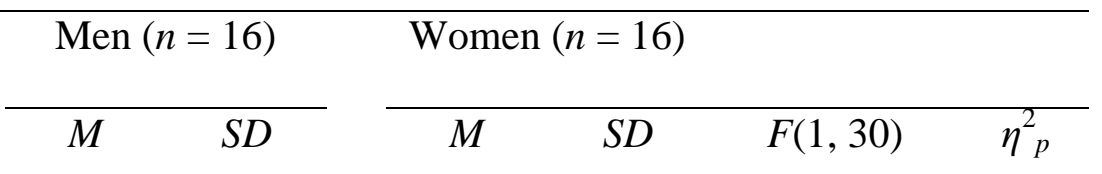

\begin{tabular}{|c|c|c|c|c|c|c|}
\hline \multicolumn{7}{|l|}{ Helpee behavior ${ }^{1}$} \\
\hline Positive & .74 & .16 & .75 & .15 & 0.09 & .00 \\
\hline Negative & .03 & .06 & .06 & .09 & 1.14 & .04 \\
\hline \multicolumn{7}{|l|}{ Helper behavior ${ }^{1}$} \\
\hline Emotional & .53 & .19 & .54 & .17 & 0.04 & .00 \\
\hline Instrumental & .21 & .15 & .24 & .13 & 0.33 & .01 \\
\hline Negative & .09 & .11 & .11 & .16 & 0.26 & .01 \\
\hline Perceived support $^{2}$ & 4.38 & 1.04 & 4.28 & 1.24 & 0.06 & .00 \\
\hline
\end{tabular}

